\title{
How do loyalty programs affect goodwill? An optimal control approach
}

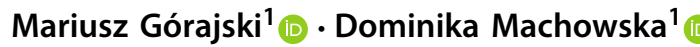

Received: 28 February 2018 / Revised: 10 August 2018 / Published online: 5 October 2018

(c) The Author(s) 2018

\begin{abstract}
This paper examines the long-term impact of loyalty programs on a company's profit and reputation among customers, and with different durations of product use. We analyze how the launch of loyalty programs may change the profitability of optimal advertising activities. The basis of this study is a modified goodwill model where the market is segmented according to usage experience. The main novelty is the role of loyalty programs and consumer recommendations in the creation of product goodwill, and also their influence on optimal advertising. The dynamics of goodwill are described by a partial differential equation. The firm maximizes the sum of discounted profits by choosing a different advertising campaign for each market segment. For a highquality product, we observe that there is a trade off between the loyalty program and optimal advertising strategies. For a low-quality product, the loyalty program causes more profitable companies to invest heavily in additional advertising efforts.
\end{abstract}

Keywords Loyalty program · Goodwill · Advertising efforts · Optimal control

Mathematics Subject Classification 49J20 · 90B60

\section{Introduction}

The relationship marketing paradigms draw particular attention to customer satisfaction and retention [see (Kotler and Keller 2006, p. 152)]; that is, it focuses on building and maintaining lasting relationships with existing customers. From the financial point of view, there is evidence that retaining current customers is much cheaper for a

Dominika Machowska

dominika.machowska@uni.lodz.pl

Mariusz Górajski

mariusz.gorajski@uni.lodz.pl

1 Department of Econometrics, Faculty of Economics and Sociology,

University of Łódź, Łódź, Poland 
company than acquiring new ones [see Reinartz (2006)]. Customer-centric marketing actions may foster customer loyalty and enhance company profit [cf. Fruchter and Sigué (2009)]. Loyalty programs (LPs) are one of the fundamental tools in relationship marketing. The traditional notion is that LPs provide an opportunity to build longer, stronger and deeper relationships with the customer [see Bolton et al. (2000)]. Therefore, companies in a variety of sectors try to outdo one another in offering their customers various kinds of LPs. For example, LPs are offered by providers of many services, including airline companies-who offer frequent flyer programs such as 'Miles and more'-, banks - for example, the LP of ING Bank Slaski, which is called 'you bank, you gain' _ _, and many merchandise retailers—-such as Tesco's ClubCard in the UK. Generally, the goal of these programs is to establish a higher level of customer retention in the profitable segments [see Bolton et al. (2000)]. Several studies have confirmed that LPs may increase customer repeat-purchase loyalty by rewarding customers for continuing business with the company [see Sharp and Sharp (1997); Hikkerova (2011)]. The next section will discuss the importance of retaining loyal customers in more detail.

Despite the fact that companies commonly use LPs as a marketing tool to affect consumer behaviour around the world, the effectiveness of LPs is still not well understood and it has been questioned by many researchers and managers [see Steinhoff and Palmatier (2016)]. Roehm et al. (2002) identify several different types of effects of LPs, including improvement, lack of improvement, and decline in brand loyalty. Dowling and Uncles (1997) summarize many empirical studies and conclude that only about 10 percent of buyers are $100 \%$ loyal to a particular brand, especially for frequently purchased products. Moreover, they find that most of the LPs may have drawbacks. However, there are also some positive examples of the introduction of LPs. Yi and Jeon (2003) and Suh and Yi (2012) present the psychological conditions under which a LP may generate and increase customer loyalty. All of these observations reveal conflicting results about the action of LPs and tend to require a deeper analysis of this marketing tool.

This paper contributes to a better understanding of the influence of LPs on the longterm perception of the product and on its reputation among consumers. The last two product's features can be well approximated by product goodwill, which is defined as a set of intangible assets that are owned by the company and which are built over a long period of time by the company's advertising activities (Kapferer 2012, p. 18). We follow suggestions from Bolton et al. (2000) and study the long-term effects of LPs on product goodwill. Therefore, we extend the seminal model of goodwill proposed by Nerlove and Arrow (1962) and we consider the influence of LPs on goodwill in the market segmented in terms of consumer usage experience. This allows us to include the impact of LP with varying degrees of consumer experience in our analysis. In our approach, we assume that the essential factors causing goodwill increase are the customer's positive experiences, which may be managed through investment in communication with them using LPs and advertising tools [see Livingston (2005) and Baranowski et al. (2018)]. In addition, the information revolution has reduced the costs associated with communicating with a consumer. Thus, advertising activities directed

$\overline{1}$ Originally, this program is known in Polish as 'bankujesz - zyskujesz'. 
to very small market segments have become technologically and financially possible [see Rust and Miu (2006)].

Moreover, previous research on LPs has reported different effects across products with distinct attributes [see Reinartz (2006)]. Therefore, in our analysis, we consider products with different quality levels. In particular, we will examine how the product's quality changes the LP's impact on goodwill and how it can affect the company's profitability. Finally, we also study how LPs impact on advertising strategies that are directed to existing and new customers. This will help us to answer the question posed by Dowling and Uncles (1997) about the different effects of LP in comparison to other marketing activities and their influence on a possible increase in company profit.

The rest of this paper is organized as follows. Section 2 briefly presents a discussion of the role of LPs from the perspective of the consumer and producer. Section 3 describes the new optimal goodwill model and how LPs affect goodwill. Section 4 derives the main results based on numerical simulations. Section 5 provides some conclusions and discusses the implications of our findings.

\section{Perspectives of a loyalty program}

In line with Noble et al. (2014), we define a LP as a marketing tool that offers customers benefits in exchange for repeat patronage to an organization. Such a program rarely benefits consumers in one purchase but is intended to foster customer loyalty over time [cf. Henderson et al. (2011)]. There are many forms of frequency reward programs and it is difficult to clearly define such a program because there is often a vague border between the LP and other forms of marketing activities [see Reinartz (2006)]. The central characteristic of loyalty programs is their long-term action that is focused on assisting consumer repeated contact with the product, the brand, or the company. A member of a LP anticipates that he or she will achieve more benefits from the purchase of these products and simultaneously resigns from the possibility of choosing other goods. In return for concentrating on a single manufacturer or supplier, the customer has the opportunity to collect points that can be exchanged for other products or services, usually but not only from the same manufacturer. Consequently, LPs have become an essential customer relationship management tool that can be used to identify, reward, and retain consumers.

Many scholars claim that it is a waste of resources to create LPs for all consumers, particularly in a heterogeneous market [cf. O'Brien and Jones (1995)]. Lacey (2015) points out that a company may deplete their capital through making a heavy investment in their customers, who are satisfied with the product but do not generate sufficient profit, instead of investing in unsatisfied clients who may significantly increase profit. Therefore, LPs should be designed to reward their most valuable customers by creating benefits based on the customer's value to the company. As a result, LPs should be diversified with respect to segments of the market. This observation is included in the new model of goodwill, where the strength of the LP depends on the market segments. 


\subsection{Customer perspective}

The main/major reason why customers join the LP is the promise to receive rewards for making purchases over a long period of time. In general, one may recognize two main groups of rewards: 'hard rewards,' such as financial (or tangible) rewards; or psychological and emotional benefits, or so-called 'soft rewards' [cf. Reinartz (2006)]. Economic value via LPs is built in many ways, including product offering and gifts, reward and gift cards, cash rebates, special deals, price discounts, extended warranties, and concessions and waivers from standard fees [see Lacey (2015)].

In contrast, the second group of benefits is connected with special recognition of the clients. They receive a special status, are treated exceptionally, and receive psychological benefits. For example, airlines prepare special, luxurious waiting areas, such as the KLM Crown Lounges. Consumers feel particularly honored when they receive a hedonistic reward, which the consumers associate with pleasure and fun. Reinartz (2006) gives the example of a free flight to an exotic destination, which may be more attractive for clients compared to a voucher for a local supermarket, even if both have the same value.

\subsection{Company perspective}

Companies initiating LPs recognize the need to build relationships with their customers. A company uses marketing schemes to try to build commitment with the brand and create a strong emotional bond with their customers.

As we have already mentioned, the LP is a system of postponed rewards that a customer gains as a result of the frequent purchase of products. Repurchase behavior generates the first and immediate benefit for the company - an increase in profit-, and in the case of a very competitive market-maintaining current sales. However, one should be aware that this is a short-term benefit, it lasts as long as the customers participate in the program. Therefore, at this initial stage, the client is more tied to the LP than to the brand, as was the marketer's original intention.

Building strong relationships with the brand is a long process and can be achieved only when customers positively evaluate the product, including its quality, the functional features of the product, the relationship between the quality of the product and its price. Additional bonuses received for participation in the LP have a positive impact on the image of the product and the entire brand in the customer's eyes. All of these factors increase product goodwill [see Liu (2007)] and, therefore, the customers will become loyal to the brand. The importance of this feature has already shown by the definition proposed by Oliver (2014), p. 432, which defines customer loyalty as 'a deeply held commitment to rebuy or repatronize a preferred product or service consistently in the future, despite situational influences and marketing efforts having the potential to cause switching behavior'. For the company, loyal customers are the most valuable. Their relationship commitment is by definition long-term and, therefore, these clients spend more than other customers, and thus generate a consistently high company profit. Moreover, the fact that these customers positively evaluate this product means that they are also less sensitive to price changes [see Dowling and Uncles 
(1997)]. Finally, Bolton et al. (2000) show that blueloyal customers are generally less sensitive to losses in the quality of the product.

Another advantage of having loyal customers is that they actively participate in word-of-mouth communication [cf. Lacey and Morgan (2008)]. It is well-known that this type of consumer communication is treated as the most trusted and many people very often rely on the opinion of others who have already utilized the product [see East et al. (2005)]. Thus, through word-of-mouth loyalty the clients encourage potential consumers to try the product and this entails the growth of goodwill among potential customers. Hence, at no additional cost or effort, the company acquires new customers [cf. Keaveney (1995) and East et al. (2005)].

Loyal consumers are tied with the product and can feel even co-responsible for it. Lacey and Morgan (2008) give empirical support for the existence of the relationship between customer commitment and marketing research support, such as testing a new product and making suggestions for improving it. They provide feedback about new product and post-test advertising. Moreover, in a situation where a consumer discovers a product defect, they usually report it. This is due to the confidence which the consumer gives the company because she or he believes that their complaint will be handled. They can also believe that this complaint will improve the product's quality

One of the most important intangible assets derived from the LP is the database of the consumers and their purchasing behavior [cf. Yi and Jeon (2003)]. Analysis of data collected from the transaction allows a better understanding of the customer's needs and behavior and provides the possibility to adapt the offer more effectively [see Nunes and Drèze (2006)] and create a new product in the future that is more suited to the market. O'Malley (1998) observes that with this information, it is possible to modify customer behavior in order to increase their value for the company.

Dowling and Uncles (1997) and Nunes and Drèze (2006) draw attention to the defensive features of LPs. In particular, LPs create barriers to exit, and they are conducted to distinguish products from competing companies and to pre-empt the entry of a new brand. They also thwart the introduction of similar programs by competitors.

\section{The optimal goodwill model}

We built on dynamic models of goodwill [e.g. Grosset and Viscolani (2005), Buratto et al. (2006), Grosset and Viscolani (2008), Favaretto and Viscolani (2010), Faggian and Grosset (2013) and Grosset and Viscolani (2016); Górajski and Machowska $(2017,2018)]$ but emphasize the role of loyalty programs in conducting the optimal advertising strategies.

\subsection{The goodwill equation}

We consider an oligopolistic industry in which companies produce homogeneous products and engage in Cournot-type competition [see Dastidar (1997)]. We focus on a single company and we omit any competitive reactions in the market to highlight the impact of LPs on the firm's performance. Managers of the company divide consumers 
into segments according to their usage experience $a \in[0,1)$. A segment $a=0$ consists of potential consumers who intend to purchase the product, however, they do not have any experience in using it. Moreover, time is measured in units of maximum duration of product use; hence, consumers with the usage experience equal to 1 leave the market permanently. Over the course of a lifetime, we stop using many products, from children's toys and clothes through teenager computer games to medicines. We may also permanently stop using many services. For example, at a certain age we do not need extreme sport life insurance because we stop such practices. Therefore, maximal usage experience strongly depends on the type of goods. We use this type of segmentation because many empirical studies confirm that the experience in using the product is essential in making purchasing decisions and in building long-term relationships between the product or the company and its customers [see Chang and Chieng (2006) and Lemon and Verhoef (2016)]. In addition, Rust and Miu (2006) indicate that new technologies allow us to create advertising strategies that are directed at very narrow market segments. Moreover, loyalty and customer retention crucially depend on the usage experience, which is highlighted in Hallowell (1996). Therefore, in our study we assume that goodwill depends on usage experience.

Managers determine the decision horizon as $T<\infty$ units of time. We denote by $G(t, a)$ the product goodwill in segment $a \in[0,1)$ and time $t \in[0, T]$. Recall that $G(t, a)$ is defined in Nerlove and Arrow (1962) and Grosset and Viscolani (2008) as that part of the product demand that results from past and current investment in advertising activities. In the sequel, we assume that $G(t, a)$ is represented by the number of consumers with usage experience $a$ who continue buying the product at time $t$ as an effect of advertising activities.

The consumer's reception of marketing efforts depends on their knowledge of the product [cf. empirical examples presented in Bruce et al. (2012)]. Therefore, we assume that advertising efforts vary in different market segments. Let $u(t, a)$ and $u_{0}(t)$ denote the intensity of advertising efforts at time $t$ in consumer segment $a \in(0,1)$, and in the segment of new consumers $(a=0)$, respectively. In line with Martín-Herrán et al. (2012), we identify by $u_{0}(t)$ offensive strategies that attract new consumers and by $u(t, a)$ defensive strategies that maintain existing consumers. Advertising intensity is measured in Gross Rating Points, which are the ratio of advertising impressions to the number of people in the audience for a marketing activity [see (Farris et al. 2009, p. 269)]. Let $I>0$ denote the maximum level of advertising efforts. We assume that $u^{\rho}(t, a)$ and $u_{0}^{\rho}(t), \rho \in(0,1]$ enhance the product's goodwill $G(t, a)$ and $G(t, 0)$, respectively, where $\rho \in(0,1)$ expresses the non-linear-concave effect of advertising efforts on goodwill [see Simon and Arndt (1980)].

In this paper, we focus on a LP and its long-term influence on profitability. In Sect. 2, we recall that the main goal of LPs is building long-term relationships with customers - that is, increase goodwill — and that LPs remain fixed during the whole decision horizon. Moreover, we have already mentioned that a LP which varies due to the experience of using the product is more effective. Therefore, let us denote by $L_{p}(a) \geq 0$ the rate of effectiveness of a LP directed to the consumer segment $a$, which positively influences product goodwill. In our approach, $L_{p}$ is an exogenous function, which is fixed by the firm's managers for each market segment individually. As a 
result, we are able to assess the effects of a LP on the optimal advertising strategies $u(t, a)$ and $u_{0}(t)$. Table 1 presents several versions of $L_{p}$.

Furthermore, there is a natural depreciation rate of goodwill $\delta_{n}(a) \geq 0$ in each segment of consumers $a$. In a natural way, consumers forget about the product or become bored with it, so $\delta_{n}$ negatively impacts on the product goodwill. On the other hand, the rate of forgetting depends on the product and its attributes and may vary between consumers with different experience in the use of the good. Therefore, we assume that this variable depends on the consumer segment that is observed for experience products [see Nelson (1974)]. For this kind of good, as time goes by, the consumers discover the features of the product and update their judgment about it, which yields changes in the depreciation rate of the goodwill. In the sequel, we assume that in each market segment the LPs reduce the goodwill depreciation rate.

Finally, the goodwill model is given by a partial differential equation of the form:

$$
\frac{\partial G(t, a)}{\partial t}+\frac{\partial G(t, a)}{\partial a}+\left(\delta_{n}(a)-q \cdot L_{p}(a)\right) G(t, a)=\lambda^{\rho} u^{\rho}(t, a),
$$

for $(t, a) \in[0, T] \times[0,1)$, where the rate of change of goodwill $\frac{\partial G(t, a)}{\partial t}$ in market segment $a$ negatively depends on the flow of product goodwill $\frac{\partial G(t, a)}{\partial a}$ from one market segment to another, and on total number of consumers $\delta_{n}(a) G(t, a)$ who depreciate. The terms which positively affect the rate of change of product goodwill in the segment $a$ represent the effects of maintaining customers by two marketing tools: advertising strategies, $\lambda^{\rho} u^{\rho}(t, a)$, and by LPs, $q \cdot L_{p}(a) G(t, a)$. The parameter $\lambda^{\rho}$ is the effectiveness of the marketing channel [see Buratto et al. (2006)] and $q$ is the effectiveness of LPs. Observe that in (1) both variables $t$ and $a$ evolve with the same speed as a consequence of the process of gaining experience by customers.

\subsection{Potential consumers}

The value of the goodwill of new consumers $G(t, 0)$ is also affected by the recommendations of the consumers with some experience in using the product $r_{n}(a)$. In addition, this consumer recommendation is enhanced by a LP $L_{p}(a)$. For clarity in description of the process of generating goodwill in the segment of potential consumers, let us consider $N(t, a)$ as the number of consumers who are willing to buy the product for the first time at moment $t$ as an effect of consumer recommendations flowing from consumers in segment $a$, and assume that

$$
N(t, a)=\left(r_{n}(a)+q \cdot L_{p}(a)\right) G(t, a),
$$

where $r_{n}(a)$ is the share of consumers in segment $a$ who have assessed the product's quality positively and $q \cdot L_{p}(a)$ is the share of clients encouraged to recommend the product due to the LP. In our approach, $r_{n}$ is an exogenous function. Hence, $N(t, a)$ is the amount of consumers in segment $a$ with a positive attitude to the product. Thus, in (2) we assume that every consumer in segment $a$ who gives a positive recommendation about the product convinces one potential consumer to buy the product. 
Finally, if we integrate $N(t, a)$ over all market segments, we obtain:

$$
\int_{0}^{1} N(t, a) d a=\int_{0}^{1}\left(r_{n}(a)+q \cdot L_{p}(a)\right) G(t, a) d a .
$$

The level of goodwill $G(t, 0)$ in the segment of new consumers is also enhanced by a variable advertising campaign $u_{0}(t)$ that is directed exclusively to this segment. Therefore, combining the influence of consumer recommendations, a LP, and advertising effort $u_{0}(t)$, we have the formal description of creating goodwill among customers without any experience in using the product; that is,

$$
G(t, 0)=\int_{0}^{1}\left(r_{n}(a)+q \cdot L_{p}(a)\right) G(t, a) d a+\lambda^{\rho} u_{0}^{\rho}(t) .
$$

As a result, the goodwill model is given by the partial differential equation (PDE) of the form:

$$
\left\{\begin{array}{l}
\frac{\partial G(t, a)}{\partial t}+\frac{\partial G(t, a)}{\partial a}+\left(\delta_{n}(a)-q \cdot L_{p}(a)\right) G(t, a)=\lambda^{\rho} u^{\rho}(t, a) \\
\left.G(t, 0)=\int_{0}^{1}\left(r_{n}(a)+q \cdot L_{p}(a)\right) G(t, a)\right) d a+\lambda^{\rho} u_{0}^{\rho}(t) \\
G(0, a)=G_{0}(a)
\end{array}\right.
$$

for all $(t, a) \in[0, T] \times[0,1)$.

\subsection{Company's profit}

The aim of the company is to choose the advertising strategies that maximize the sum of the discounted profits in a decision horizon $T<\infty$. Let $Q(t, a)$ be a demand function in segment $a$, defined by

$$
Q(t, a)=z(t, a) G(t, a),
$$

where $z(t, a)$ denotes all exogenous variables which can influence the demand (f. ex. price of the product, consumer incomes). By letting the operating cost to be linear, that is $C(Q)=C_{v} Q+C_{f}$, with unit variable cost $C_{v} \in(0,1)$ and fixed cost $C_{f}>0$, we obtain the formula for instantaneous profit:

$$
P(t, a)=Q(t, a) p(t, a)-C(Q(t, a))=G(t, a) \tilde{z}(t, a)-C_{f}
$$

where $\tilde{z}(t, a)=z(t, a)\left(p(t, a)-C_{v}\right)$. Based on the hypothesis about decreasing marginal return of advertising efforts [see Bagwell (2007)], we assume that the costs of advertising activities and LPs, denoted respectively by $C_{A}$ and $C_{L}$, are quadratic:

$$
C_{A}(u)=\frac{\beta}{2} u^{2}, \quad C_{A}\left(u_{0}\right)=\frac{\beta}{2} u_{0}^{2}, \quad C_{L}\left(L_{p}\right)=\frac{\beta}{2} L_{p}^{2}(t),
$$

where $\frac{\beta}{2}>0$ is the unit price of marketing efforts. 
Hence, the sum of discounted profits over the decision horizon $T$ is given by

$$
\begin{aligned}
J\left(u, u_{0}\right) & \left.=\int_{0}^{1} \int_{0}^{T} e^{-r t}\left(P(t, a)-C_{A}(u(t, a))-C_{A}\left(u_{0}(t)\right)-C_{L}\left(L_{p}(a)\right)\right)\right) d t d a \\
& =\int_{0}^{1} \int_{0}^{T} e^{-r t}\left(\tilde{z}(t, a) G(t, a)-\frac{\beta}{2}\left(u^{2}(t, a)+u_{0}^{2}(t)+L_{p}^{2}(a)\right)-C_{f}\right) d t d a,
\end{aligned}
$$

where $r>0$ is the force of interest.

Therefore, we obtain the optimal control problem (3)-(7), where we choose advertising efforts that are different for each market segment to maximize the sum of discounted profits over the decision horizon $T$. The formulas for the optimal advertising strategies are presented in the Appendix. These tools allow us to analyze how different LPs influence goodwill, optimal advertising strategies, and company profit. The analysis is based on the numerical simulations that are presented in the next section.

\section{Simulation results}

Based on the numerical solution of (9) with (10)-(11), we are able to determine the optimal advertising strategies and corresponding goodwill paths for different managerial problems. In our model simulations we consider several scenarios to evaluate the effects of introducing new LP on advertising strategies.

We consider two different durable products or services sold on a market. It is assumed that the companies recognize the need for segmentation of the market in which they sell their goods and, therefore, the market is divided in terms of the consumer's usage experience.

Both products or services are experience goods; that is, goods whose particular attributes are recognized by consumers after some time of using them [see Nelson (1974)]. This study also takes into account the perceived quality of the product, which significantly influences purchasing decisions and the willingness to provide consumer recommendations [cf. Gobinath and Gupta (2016)]. We assume that the first good is of low quality. Hence, the number of consumers who negatively evaluate this good increases with time and, as time goes by, more consumers cease to use it. The direct consequence is that fewer and fewer positive consumer recommendations appear, particularly among consumers with a longer experience because they have had time to familiarize themselves with the defects of the product. Therefore, for this product, one can observe an increasing depreciation rate of goodwill $\delta_{n}$ and a decreasing recommendation function $r_{n}$ with respect to usage experience. The second is a high-quality product. In this case, the situation is reversed. The longer the usage experience is, the more positive attributes are discovered by the consumers. This implies that more consumers become attached to this good. This is reflected by the decreasing depreciation rate of goodwill $\delta_{n}$ and an increasing number of positive recommendations $r_{n}$ of the product, particularly among consumers with longer usage experience. 
Table 1 The forms of function, describing the LP, $L_{p}(a)$, the rate of consumer recommendation, $r_{n}(a)$ and the goodwill depreciation rate, $\delta_{n}(a)$, for all market segments $a \in[0,1]$

\begin{tabular}{lll}
\hline & High-quality product & Low-quality product \\
\hline $\begin{array}{l}\text { Natural } \\
\text { depreciation rate }\end{array}$ & $\delta_{n}(a)=-0.2 a+0.5, \operatorname{mean}\left(\delta_{n}\right)=0.4$ & $\delta_{n}(a)=0.4 a+0.6, \operatorname{mean}\left(\delta_{n}\right)=0.8$ \\
$\begin{array}{l}\text { Consumer } \\
\text { recommendation }\end{array}$ & $r_{n}(a)=0.4 a+0.6, \operatorname{mean}\left(r_{n}\right)=0.8$ & $r_{n}(a)=-0.4 a+0.6, \operatorname{mean}\left(r_{n}\right)=0.4$ \\
LP & $L_{p}(a)=l \cdot a$, where $l \in\{0,0.1,0.2,0.3\}$ \\
\hline
\end{tabular}

We assume that the company influences the levels of goodwill by their advertising activities, such as a LP. A LP $L_{p}$ may impact the level of the goodwill depreciation rate. A well-received LP encourages them to remain customers of the company and, hence, the depreciation rate decreases. It can also stimulate the number of product recommendations, as we have previously mentioned in Sect. 2.2. We consider four different situations related to the effectiveness of LPs. First, we analyze the experiments without any influence of LP; that is, $L_{p}=0$. Next, we assume that LPs depend on usage experience because the customer with a long experience is usually a long time member of a LP. The basic idea of a LP is that the postponed rewards are more valuable for long-standing members. This means that customers with a longer experience may be more satisfied with the LP and, therefore, we assume that $L_{p}(a)$ increases with respect to usage experience. In addition, the high mean value of $L_{p}$ reflects the more effective and better received LP.

In summary, we consider several experiments corresponding to different levels of the product quality and effectiveness of the LP. Table 1 contains the formulas of $L_{p}$, $\delta_{n}$ and $r_{n}$, and their mean values.

To highlight the impact of the product's quality and the operation of the LPs, the other model parameters are left unchanged in each simulation. Next, we assume that the advertising response function $(\rho=0.5)$ has a concave-downward shape [see Simon and Arndt (1980)]. Moreover, the initial level of goodwill is $G_{0}=10$, the maximum advertising effort is $I=45$, and the unit cost of advertising is $\beta=0.00008$. We set the continuous interest rate $r=2.5 \%$, the effectivenness of LPs advertising efforts are $q=1$ and $\lambda=1$, respectively.

The results of four representative simulations are shown in Figs. 1, 2, 3 and 4. Each graphical presentation consists of the following three plots (from left to right): the contour plot of the optimal advertising strategy directed to existing customers $u^{*}$, the plot of the optimal advertising strategy directed to potential customers $u_{0}^{*}$, and a $3 \mathrm{D}$ plot of optimal goodwill paths.

We recognize two types of optimal advertising strategies, which we will call 'supportive' and 'strengthening'. The first maintains the level of goodwill at most at its initial level, while the latter causes a significant increase in the level of goodwill from its initial value. Strengthening strategies occur if the product is of high quality (see Figs. 1 and 2). For almost the whole period of the decision-making, goodwill is higher in segments of customers with shorter experience. The growth of the effectiveness of LPs causes the averages of goodwill to increase, especially at the end of the decision- 

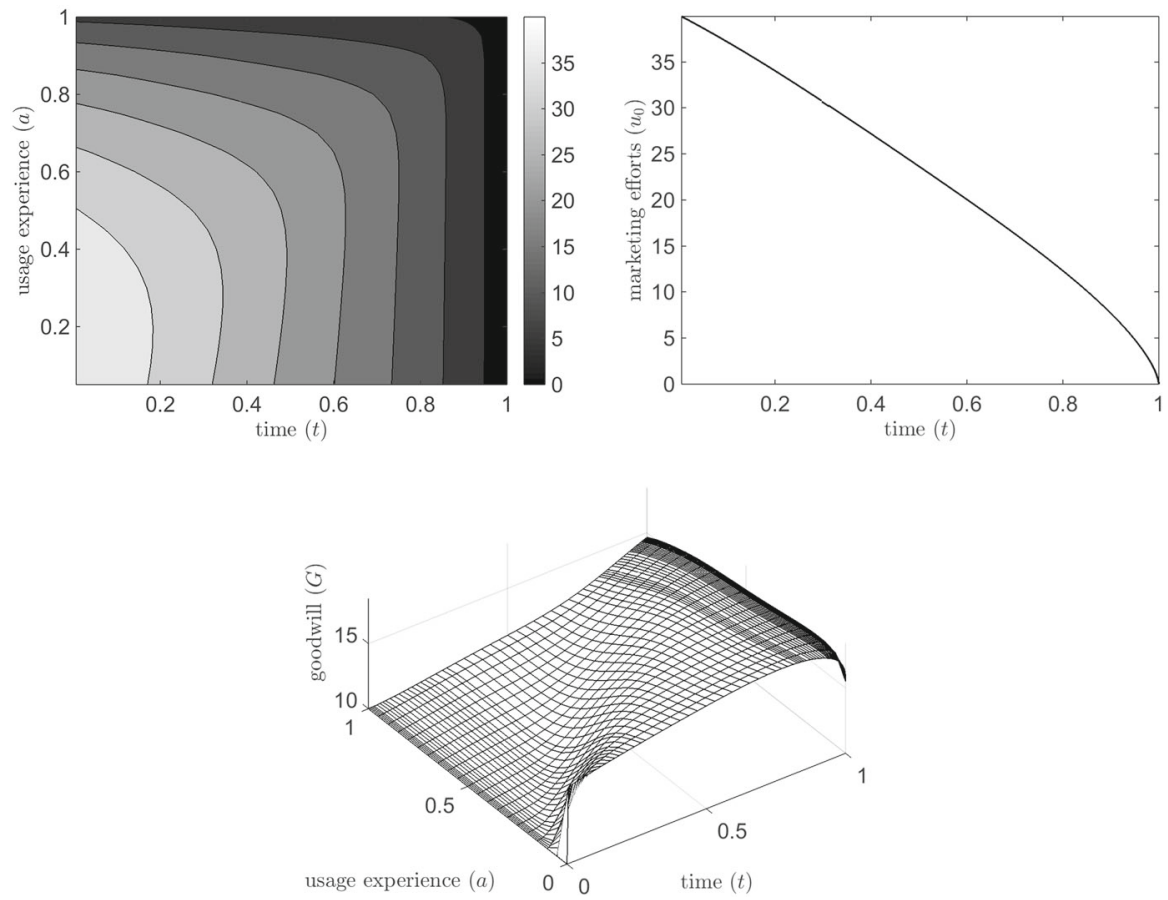

Fig. 1 The experiment for the most effective LP and high-quality good with $L_{p}(a)=0.3 a, \operatorname{mean}\left(\delta_{n}\right)=0.4$, mean $\left(r_{n}\right)=0.8$

making period (see also Table 3). In our experiments, the most effective LP causes an increase in the average level of goodwill by $20 \%$ compared to the model without any LP.

The supporting strategies are found in the scenarios with low-quality goods (see Figs. 3 and 4). For this type of product, we observe that very effective LPs may enhance the mean value of goodwill by approximately $19 \%$ but all the averages are below the initial level. Hence, when the quality of product is low, it is difficult to increase the goodwill in all market segments above its initial level.

All optimal advertising strategies have a concave decreasing shape. This means that in each market segment, the maximum level of optimal advertising intensity is reached at the beginning of the decision-making period. The main differences are in the value of the maximum level of optimal strategies. Consumers with shorter usage experiences require higher values of advertising intensity compared to more experienced users. We also observe that the acquisition of new customers is much more difficult and more expensive than maintaining existing ones because the mean values of advertising strategies directed to new customers $\left(u_{0}^{*}\right)$ are higher than those directed to existing customers $\left(u^{*}\right)$ (see Tables 2 and 3 ). This finding was also observed in previous studies [cf. Fruchter and Sigué (2009)].

Moreover, the growth in the efficiency of LPs cause the maximal levels of optimal advertising to increase. In each case, the maximum values of $u_{0}^{*}$ and $u^{*}$ are the same. 

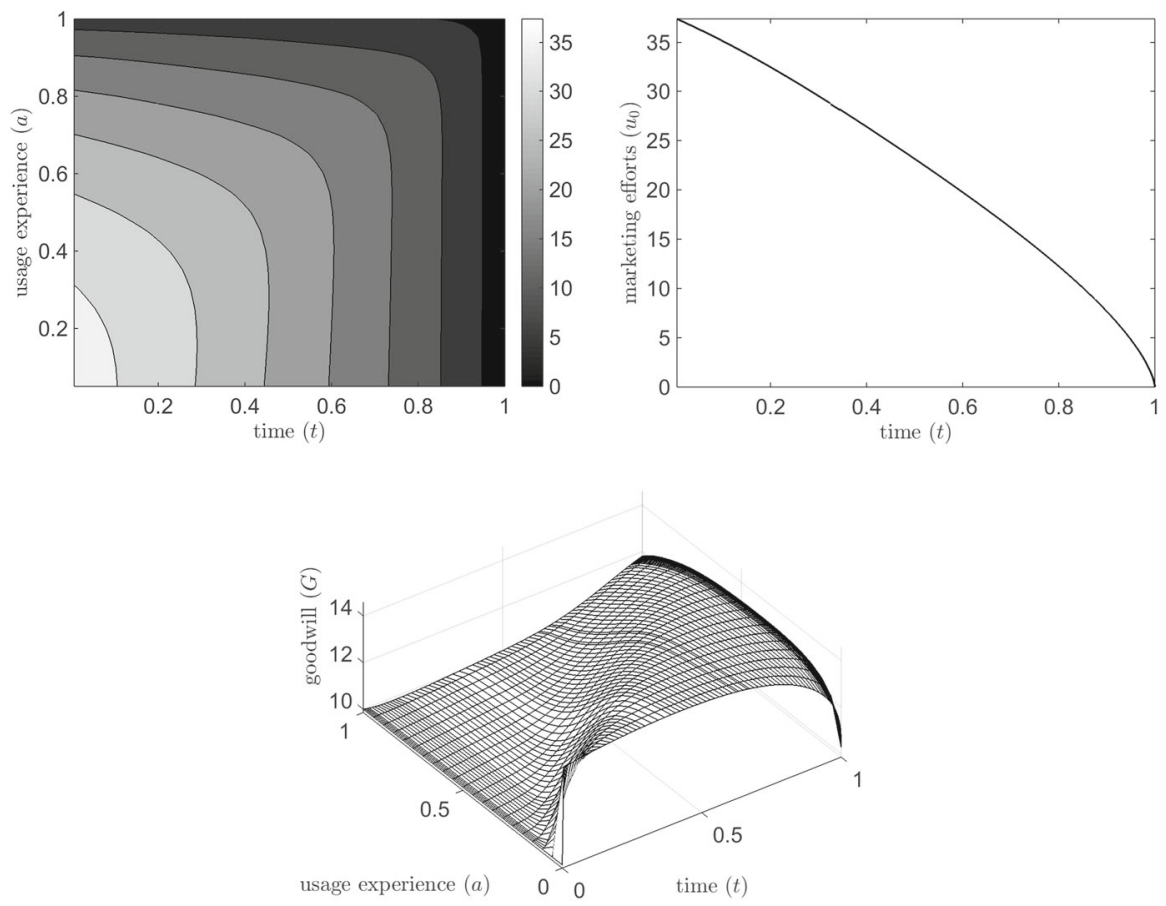

Fig. 2 The experiment for no LP and high-quality good with $L_{p}(a)=0$, mean $\left(\delta_{n}\right)=0.4, \operatorname{mean}\left(r_{n}\right)=0.8$

However, for the high and low-quality products, the average values of optimal strategies respond differently to changes in the effectiveness of LPs. First, for a product of high quality, we observe that there is a trade off between the effectiveness of LPs and other advertising activities. More precisely, the growth in a LP's effectiveness causes a reduction in the averages of both advertising strategies. This means that an effective LP that applies for a high-quality product does not require as much effort of advertising activities in comparison to a situation where managers do not introduce the LP. Second, the behavior of the control variables are different for a product of low quality, and we observe a simultaneous increase in the strength of both LPs and advertising. An effective LP causes the additional advertising efforts to become profitable and this brings a significant increase in profit.

An interesting finding of all the simulations is that in the segment of consumers with the longest usage experience, the level of goodwill does not undergo as big a fluctuation as it does in segments of consumers with a short experience. This observation is consistent with empirical psychological and advertising research, which emphasizes that consumers who are familiar with the product are guided in their purchasing decisions by their experience and are not very sensitive to the action of advertising and other advertising tools. Even consumer recommendations do not affect their decisions.

Finally, we also analyse how the product quality and effectiveness of LPs affect the value of the total profit (see Tables 2 and 3). 

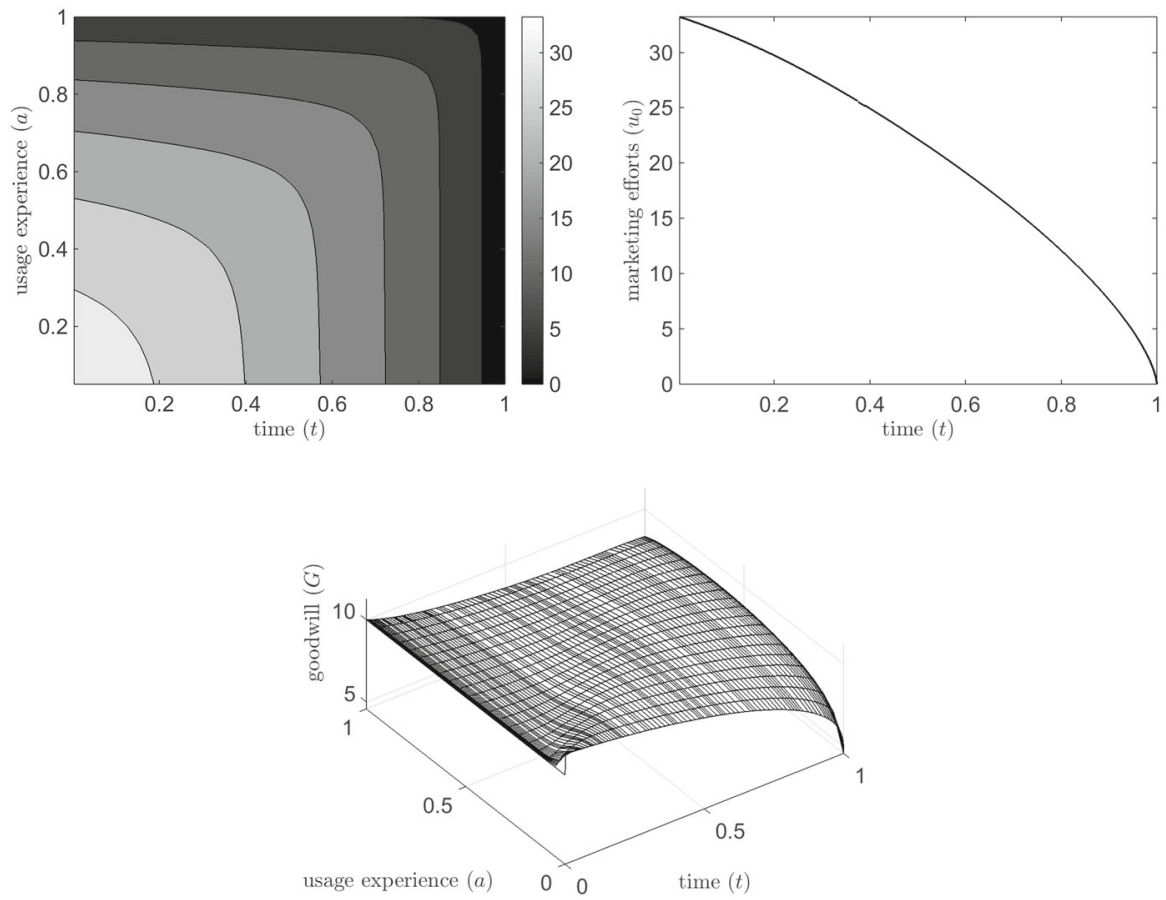

Fig. 3 The experiment for the most effective LP and low-quality good with $L_{p}(a)=0.3 a, \operatorname{mean}\left(\delta_{n}\right)=0.8$, $\operatorname{mean}\left(r_{n}\right)=0.4$

At the beginning of this paper we discussed the effect of an investment in LP on a company's profit. Despite the additional costs associated with the launch of a LP, the company still notes a growth of profits. For both types of product, if the company does not invest in advertising activities, then the increase in intensity of LPs causes the profit $\left(J_{0}\right)$ to grow by $17 \%$. A similar observation can be achieved by taking into account investment in optimal advertising activities. In this situation, the profit $(J)$ increases by up to $15 \%$. It is not surprising that the highest value of profits is achieved by companies with a high-quality product and an additional investment in the most effective LP.

It is worth noting that the increase in profit from the sale of a high-quality product is equal to $46 \%$ when compared to the profit from the sale of a low-quality product for the same level of LP's effectiveness. Despite the fact that the model does not take into account the increased production cost of a high-quality product, it is worth remembering how profit from the sale of this type of product may increase when it is effectively promoted using different marketing tools.

We also analyze the profitability of the optimal advertising strategies at different levels of efficiency LP. Consequently, in Tables 2 and 3, the ratio $\frac{\Delta J}{J_{0}}$ is a measure of the benefit from the advertising campaigns and it is equal to the percentage change of the company profits caused by introducing the optimal advertising strategies. 

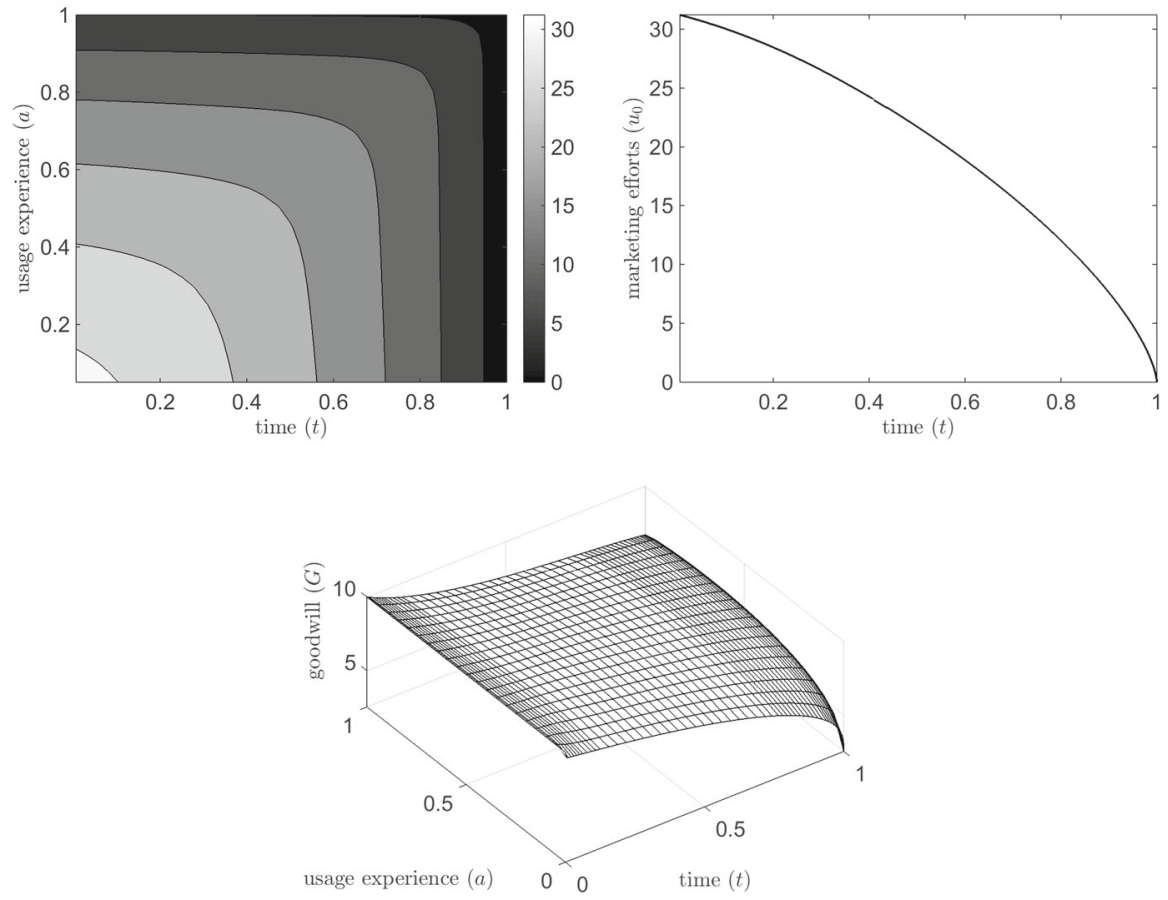

Fig. 4 The experiment for no LP and low-quality good with $L_{p}(a)=0, \operatorname{mean}\left(\delta_{n}\right)=0.8, \operatorname{mean}\left(r_{n}\right)=0.4$

Table 2 Company benefits from advertising efforts and LPs for a low-quality product. $J_{0}$ is the company's profit without advertising investment, $J$ is the company's profit with optimal advertising investment

\begin{tabular}{lllllllll}
\hline $\mathrm{LP}$ & $J_{0}$ & $J$ & $\Delta J / J_{0}(\%)$ & $\operatorname{mean}\left(u^{*}\right)$ & $\operatorname{mean}\left(u_{0}^{*}\right)$ & $\max \left(u^{*}\right)$ & $\max \left(u_{0}^{*}\right)$ & $\operatorname{mean}\left(G^{*}\right)$ \\
\hline$L_{p}(a)=0$ & 1.56 & 2.53 & 62.18 & 11.9 & 15.65 & 31.2 & 31.2 & 8.03 \\
$L_{p}(a)=0.1 a$ & 1.65 & 2.64 & 60.00 & 13.4 & 17.87 & 31.84 & 31.84 & 8.61 \\
$L_{p}(a)=0.2 a$ & 1.74 & 2.77 & 59.20 & 15.12 & 20 & 32.52 & 32.52 & 9.11 \\
$L_{p}(a)=0.3 a$ & 1.83 & 2.9 & 58.47 & 15.66 & 20.31 & 33.21 & 33.21 & 9.52 \\
\hline
\end{tabular}

Table 3 Company benefits from advertising efforts and LPs for high-quality product. $J_{0}$ is the company's profit without advertising investment, $J$ is the company's profit with optimal advertising investment

\begin{tabular}{lllllllll}
\hline $\mathrm{LP}$ & $J_{0}$ & $J$ & $\Delta J / J_{0}(\%)$ & $\operatorname{mean}\left(u^{*}\right)$ & $\operatorname{mean}\left(u_{0}^{*}\right)$ & $\max \left(u^{*}\right)$ & $\max \left(u_{0}^{*}\right)$ & $\operatorname{mean}\left(G^{*}\right)$ \\
\hline$L_{p}(a)=0$ & 2.4 & 3.67 & 52.92 & 14.51 & 17.69 & 37.36 & 37.36 & 12.19 \\
$L_{p}(a)=0.1 a$ & 2.53 & 3.85 & 52.17 & 13.82 & 16.65 & 38.19 & 38.19 & 12.94 \\
$L_{p}(a)=0.2 a$ & 2.65 & 4.04 & 52.45 & 13.93 & 16.67 & 39.05 & 39.05 & 13.69 \\
$L_{p}(a)=0.3 a$ & 2.81 & 4.23 & 50.53 & 13.44 & 15.93 & 39.99 & 39.93 & 14.61 \\
\hline
\end{tabular}


On average, in the case of a low-quality product, a company's profit increases by $60 \%$ due to optimal advertising activities. Moreover, the increase in effectiveness of LP generates a slight decrease in benefits form advertising activities. For a high-quality product, the profit growth is lower by 8 p.p. and again the effectiveness of LP declines the return from investment in $u^{*}$ and $u_{0}^{*}$ and we observe that the effectiveness of optimal advertising strategies is limited. This observation may be interpreted as follows: a highquality product reinforced by a LP will sell itself. Advertising activities remind us only about the existence of the product and they do not have to tout its attributes because these are widely discussed by the consumer and their recommendations.

Finally, we observe that advertising strategies can be the most profitable tool for products of low quality and, above all, if the company does not introduce LPs.

\section{Conclusions}

We analysed a dynamic optimal control model of product goodwill, whose dynamics are affected by LPs and non-linear advertising activities differentiated by customer usage experience. We enhanced previous research by introducing the novel mechanism of recruiting new consumers, which is based on LPs and consumer recommendations.

The scenarios that we have presented appear to be representations of eight strategies, which are differentiated with respect to the quality of product and the effectiveness of a LP. We demonstrated that, for a set of plausible model parameters, the optimal advertising strategies can either be strengthening or supporting. Moreover, each has a different shape and achieves a specific level for a market segment. Hence, one should take into account consumer diversity because we can significantly affect the company's profit by identifying those consumer segments in which the product is evaluated positively.

Moreover, we have confirmed that LPs have a positive impact on product goodwill and company profit. However, the effect of LPs on the optimal advertising strategies for a product of low and high quality is very different. For a high-quality product, we observe that there is a trade off between the LP and optimal advertising strategies; that is, the increase in effectiveness of LP causes the decrease in the average advertising activities. Whereas for the low-quality product, LPs mean that it is more profitable for companies to invest heavily in additional advertising efforts. We have shown that in both cases (i.e., a product of low and high quality), the maximum advertising effort targeted to existing and new customers is higher when a company introduces a LP. These actions necessarily entail an increase in the company's profit.

Clearly, there are some limitations to this model approach and it is not possible with normative models to capture all of the complexities of real market environments. We believe that this investigation complements and extends our understanding of the relationships between LPs, advertising, and product goodwill.

Acknowledgements The authors gratefully acknowledge financial support from the National Science Centre in Poland. Decision number: DEC-2011/03/D/HS4/04269. 


\section{Compliance with ethical standards}

Conflict of interest The authors declare that they have no conflict of interest.

Open Access This article is distributed under the terms of the Creative Commons Attribution 4.0 International License (http://creativecommons.org/licenses/by/4.0/), which permits unrestricted use, distribution, and reproduction in any medium, provided you give appropriate credit to the original author(s) and the source, provide a link to the Creative Commons license, and indicate if changes were made.

\section{Appendix}

Definition 1 The triplet $\left(G^{*}, u^{*}, u_{0}^{*}\right)$ is an optimal solution to the problem of maximizing (7) subject to (3) if $G^{*}$ is a generalized mild solution ${ }^{2}$ to (3) with $\left(u^{*}, u_{0}^{*}\right) \in$ $U_{a d} \times U_{0, a d}$ and

$$
J\left(u^{*}, u_{0}^{*}\right) \geq J\left(u, u_{0}\right)
$$

holds for any admissible controls $\left(u, u_{0}\right) \in U_{a d} \times U_{0, a d}$ and $G=G\left(u, u_{0}\right)$ satisfying (3). The sets of admissible controls are defined by

$$
\begin{aligned}
U_{a d} & =\left\{u \in L^{\infty}((0, T) \times(0,1)): 0 \leq u(t, a) \leq I \text { for a.e. }(t, a) \in[0, T] \times[0,1]\right\}, \\
U_{0, a d} & =\left\{u_{0} \in L^{\infty}(0, T): 0 \leq u_{0}(t) \leq I \text { for a.e. } t \in[0, T]\right\} .
\end{aligned}
$$

for some $I \in(0, \infty]$.

In Górajski and Machowska (2017), it is proven that there exists the optimal solution $\left(G^{*}, u^{*}, u_{0}^{*}\right)$ to problem of maximizing (7) subject to (3).

Next, we give the conditions that characterize the optimal solution $\left(G^{*}, u^{*}, u_{0}^{*}\right)$. First, we claim based on Proposition 2 from Feichtinger et al. (2003) that there exists a unique solution $\xi:[0, T] \times[0,1] \rightarrow \mathbb{R}$ of the adjoint system:

$$
\left\{\begin{array}{l}
\frac{\partial \xi(t, a)}{\partial t}+\frac{\partial \xi(t, a)}{\partial a}=\tilde{z}(t, a) e^{-r t}+\xi(t, a)\left(\delta_{n}(a)-q \cdot L_{p}(a)\right)-\xi(t, 0)\left(r_{n}(a)+q \cdot L_{p}(a)\right), \\
\xi(t, 1)=0 \\
\xi(T, a)=0
\end{array}\right.
$$

for all $(t, a) \in[0, T] \times[0,1]$ In the next step, we define the Hamiltonian associated with boundary condition

$$
\begin{aligned}
H_{b}\left(t, u_{0}\right)= & \xi(t, 0)\left(\int_{0}^{1}\left(r_{n}(a)+q \cdot L_{p}(a)\right) G^{*}(t, a) d a+\lambda^{\rho} u_{0}^{\rho}\right) \\
& -\int_{0}^{1} e^{-r t}\left(\tilde{z}(t, a) G^{*}(t, a)-\frac{\beta}{2}\left(u^{* 2}(t, a)+L_{p}^{2}(a)\right)\right) d a+e^{-r t} \frac{\beta}{2} u_{0}^{2},
\end{aligned}
$$

$\overline{2}$ The definition of generalized mild solution is formulated in Górajski and Machowska (2017). 
for a.e. $t \in[0, T]$ and every $u_{0} \in[0, I]$, and the distributed Hamiltonian which takes the form

$$
\begin{aligned}
H(t, a, u)= & -e^{-r t}\left(\tilde{z}(t, a) G^{*}(t, a)-\frac{\beta}{2}\left(u^{2}+u_{0}^{* 2}(t)+L_{p}^{2}(a)\right)\right) \\
& -\xi(t, a)\left(\left(\delta_{n}(a)-q \cdot L_{p}(a)\right) G^{*}(t, a)-\lambda^{\rho} u^{\rho}(t, a)\right) \\
& +\xi(t, 0)\left(r_{n}(a)+q \cdot L_{p}(a)\right) G^{*}(t, a)
\end{aligned}
$$

for a.e. $(t, a) \in[0, T] \times[0,1]$ and every $u \in[0, I]$.

Relying on the maximum principle introduced in Feichtinger et al. (2003), the optimal solution $\left(G^{*}, u^{*}, u_{0}^{*}\right)$ satisfies the following system:

$$
\left\{\begin{array}{l}
\frac{\partial G^{*}(t, a)}{\partial t}+\frac{\partial G^{*}(t, a)}{\partial a}+\left(\delta_{n}(a)-q \cdot L_{p}(a)\right) G^{*}(t, a)=\lambda^{\rho}\left(u^{*}(t, a)\right)^{\rho}, \\
G^{*}(t, 0)=\int_{0}^{1}\left(r_{n}(a)+q \cdot L_{p}(a)\right) G^{*}(t, a) d a+\lambda^{\rho}\left(u_{0}^{*}(t)\right)^{\rho}, \\
G^{*}(0, a)=G_{0}(a), \\
\frac{\partial \xi(t, a)}{\partial t}+\frac{\partial \xi(t, a)}{\partial a}=\tilde{z}(t, a) e^{-r t}+\xi(t, a)\left(\delta_{n}(a)-q \cdot L_{p}(a)\right)-\xi(t, 0)\left(r_{n}(a)+q \cdot L_{p}(a)\right), \\
\xi(T, a)=0 \\
\xi(t, 1)=0
\end{array}\right.
$$

for all $(t, a) \in[0, T] \times[0,1]$, where $\left(u^{*}, u_{0}^{*}\right)$ are given by (11) and (10):

$$
u_{0}^{*}(t)= \begin{cases}0 & \text { for } \xi(t, 0)>0 \\ \left(-\frac{\rho \lambda^{\rho}}{\beta} e^{r t} \xi(t, 0)\right)^{\frac{1}{2-\rho}} & \text { for } \xi(t, 0) \in\left[0,-\frac{\beta}{\rho \lambda^{\rho}} e^{-r t} I^{2-\rho}\right] \\ I & \text { for } \xi(t, 0)<-\frac{\beta}{\rho \lambda^{\rho}} e^{-r t} I^{2-\rho}\end{cases}
$$

and

$$
u^{*}(t, a)= \begin{cases}0 & \text { for } \xi(t, a)>0 \\ \left(-\frac{\rho \lambda^{\rho}}{\beta} e^{r t}(\xi(t, a))\right)^{\frac{1}{2-\rho}} & \text { for } \xi(t, a) \in\left[0,-\frac{\beta}{\rho \lambda^{\rho}} e^{-r t} I^{2-\rho}\right] \\ I & \text { for } \xi(t, a)<-\frac{\beta}{\rho \lambda^{\rho}} e^{-r t} I^{2-\rho}\end{cases}
$$

for a.e. $(t, a) \in[0, T] \times[0,1]$.

The system of Eqs. (9) with (10)-(11) does not possess an analytical solution. Therefore, in order to solve it, we apply the algorithm described in Górajski and Machowska (2017) which relies on the discretization of the space variable $a$ [see also the method of the line in (Schiesser and Griffiths 2009, p. 6)]. Let us denote a uniform grid of market segments as $\left\{a_{0}=0, a_{1}, \ldots, a_{N}=1\right\}$, thus the diameter of this division is given by $\Delta a=\Delta a_{i}=a_{i}-a_{i-1}$ for $i=1, \ldots, N$. We apply the composite trapezoidal rule for the approximation of the definite integral (Gautschi 1997, p. 153) 


$$
\int_{0}^{1}\left(r_{n}(a)+q \cdot L_{p}(a)\right) G^{*}(t, a) d a \approx \Delta a\left(\frac{1}{2} f_{1}(t)+\sum_{i=2}^{N-1} f_{i}(t)+\frac{1}{2} f_{N}(t)\right),
$$

where for $i=1, \ldots, N$ we denote $f_{i}(t)=\left(r_{n, i}+q \cdot L_{p, i}\right) G_{i}^{*}(t), G_{i}^{*}(t)=G^{*}\left(t, a_{i}\right)$, $L_{p, i}=L_{p}\left(a_{i}\right)$ and $r_{n, i}=r_{n}\left(a_{i}\right)$. Based on the explicit and the implicit Euler schemes for the approximation of derivatives we obtain:

$$
\begin{aligned}
& \frac{\partial G^{*}\left(t, a_{i}\right)}{\partial a}=\frac{G_{i}^{*}(t)-G_{i-1}^{*}(t)}{\Delta a}, \quad \text { for } i=1,2, \ldots, N \\
& \frac{\partial \xi\left(t, a_{i}\right)}{\partial a}=\frac{\xi_{i+1}(t)-\xi_{i}(t)}{\Delta a}, \quad \text { for } i=0,1, \ldots, N-1 .
\end{aligned}
$$

where $\xi_{i}(t)=\xi\left(t, a_{i}\right)$.

As a result we are able to transform (9) into the system of $2 \mathrm{~N}$ ordinary differential equations. Thus, we have for $i=0,1, \ldots, N$

$$
\left\{\begin{array}{l}
\frac{d G_{i}^{*}(t)}{d t}=-G_{i}^{*}(t)\left(\delta_{n, i}-q \cdot L_{p, i}+\frac{1}{\Delta a}\right)+\frac{1}{\Delta a} G_{i-1}^{*}(t)+\left(\lambda u_{i}^{*}(t)\right)^{\rho}, \\
G_{0}^{*}(t)=\Delta a\left(\frac{1}{2} f_{1}(t)+\sum_{i=2}^{N-1} f_{i}(t)+\frac{1}{2} f_{N}(t)\right)+\left(\lambda u_{0}^{*}(t)\right)^{\rho}, \\
G_{i}^{*}(0)=G_{0, i}^{*}, \\
\frac{d \xi_{i}(t)}{d t}=e^{-r t} \tilde{z}_{i}(t)-\xi_{0}(t)\left(r_{n, i}+q L_{p, i}\right)+\xi_{i}(t)\left(\delta_{n, i}-q \cdot L_{p, i}+\frac{1}{\Delta a}\right)-\frac{1}{\Delta a} \xi_{i+1}(t), \\
\xi_{N}(t)=0, \\
\xi_{i}(T)=0, \\
f_{i}(t)=G_{i}^{*}(t)\left(r_{n, i}+q L_{p, i}\right)+\left(\lambda u_{i}^{*}(t)\right)^{\rho}
\end{array}\right.
$$

for $\delta_{n, i}=\delta_{n}\left(a_{i}\right)$ and controls $u_{0}, u_{i}^{*}$ given by

$$
u_{0}^{*}(t)= \begin{cases}0 & \text { for } \xi_{0}(t)>0, \\ \left(-\frac{\rho \lambda^{\rho}}{\beta} e^{r t} \xi_{0}(t)\right)^{\frac{1}{2-\rho}} & \text { for } \xi_{0}(t) \in\left[0,-\frac{\beta}{\rho \lambda^{\rho}} e^{-r t} I^{2-\rho}\right] \\ I & \text { for } \xi_{0}(t)<-\frac{\beta}{\rho \lambda^{\rho}} e^{-r t} I^{2-\rho}\end{cases}
$$

and

$$
u_{i}^{*}(t)= \begin{cases}0 & \text { for } \xi_{i}(t)>0 \\ \left(-\frac{\rho \lambda^{\rho}}{\beta} e^{r t}\left(\xi_{i}(t)\right)\right)^{\frac{1}{2-\rho}} & \text { for } \xi_{i}(t) \in\left[0,-\frac{\beta}{\rho \lambda^{\rho}} e^{-r t} I^{2-\rho}\right] \\ I & \text { for } \xi_{i}(t)<-\frac{\beta}{\rho \lambda^{\rho}} e^{-r t} I^{2-\rho}\end{cases}
$$

respectively for $i=1, \ldots, N$.

As a result, we obtain a nonlinear boundary value problem which we solve with Matlab solver $b v p 5 c$. 


\section{References}

Bagwell K (2007) The economic analysis of advertising. Handb Ind Org 3:1701-1844

Baranowski P, Komor M, Wójcik S (2018) Whose feedback matters? Empirical evidence from online auctions. App Econ Lett 25(17):1226-1229

Bolton RN, Kannan PK, Bramlett MD (2000) Implications of loyalty program membership and service experiences for customer retention and value. J Acad Market Sci 28(1):95-108

Bruce NI, Foutz NZ, Kolsarici C (2012) Dynamic effectiveness of advertising and word of mouth in sequential distribution of new products. J Market Res 49(4):469-486

Buratto A, Grosset L, Viscolani B (2006) Advertising a new product in a segmented market. Eur J Oper Res 175(2):1262-1267

Chang PL, Chieng MH (2006) Building consumer-brand relationship: a cross-cultural experiential view. Psychol Market 23(11):927-959

Dastidar KG (1997) Comparing Cournot and Bertrand in a homogeneous product market. J Econ Theory 75(1):205-212

Dowling GR, Uncles M (1997) Do customer loyalty programs really work? Sloan Manag Rev 38(4):71-82

East R, Hammond K, Lomax W, Robinson H (2005) What is the effect of a recommendation? Market Rev 5(2):145-157

Faggian S, Grosset L (2013) Optimal advertising strategies with age-structured goodwill. Math Method Oper Res 78(2):259-284

Farris PW, Bendle NT, Pfeifer PE, Reibstein DJ (2009) Key marketing metrics: the 50+ metrics every manager needs to know. Financial Times Prentice-Hall, Upper Saddle River

Favaretto D, Viscolani B (2010) Advertising and production of a seasonal good for a heterogeneous market. 4OR 8(2):141-153

Feichtinger G, Tragler G, Veliov V (2003) Optimality conditions for age-structured control systems. J Math Anal Appl 288(1):47-68

Fruchter GE, Sigué SP (2009) Social relationship and transactional marketing policies_maximizing customer lifetime value. J Optim Theory Appl 142(3):469-492

Gautschi W (1997) Numerical analysis: an introduction. Birkhauser, Boston

Gobinath J, Gupta D (2016) Online reviews: determining the perceived quality of information. In: 2016 international conference on advances in computing, communications and informatics (ICACCI), IEEE, pp 412-416

Górajski M, Machowska D (2017) Optimal boundary control problem for a PDE model of goodwill dynamic. Math Method Oper Res 85(3):425-452

Górajski M, Machowska D (2018) The effects of technological shocks in an optimal goodwill model with a random product life cycle. Comput Math Appl 76(4):905-922

Grosset L, Viscolani B (2005) Advertising for the introduction of an age-sensitive product. Optim Control Appl Methods 26:157-167

Grosset L, Viscolani B (2008) Advertising in a segmented market: comparison of media choices. IMA J Manag Math 19(3):219-226

Grosset L, Viscolani B (2016) Age-structured linear-state differential games. Eur J Oper Res 254(1):269_ 278

Hallowell R (1996) The relationships of customer satisfaction, customer loyalty, and profitability: an empirical study. Int J Serv Ind Manag 7(4):27-42

Henderson CM, Beck JT, Palmatier RW (2011) Review of the theoretical underpinnings of loyalty programs. J Consum Psychol 21(3):256-276

Hikkerova L (2011) The effectiveness of loyalty programs: an application in the hospitality industry. Int J Bus 16(2): 150

Kapferer JN (2012) The new strategic brand management: advanced insights and strategic thinking. Kogan Page, London

Keaveney SM (1995) Customer switching behavior in service industries: an exploratory study. J Market 59(2):71-82

Kotler P, Keller K (2006) Marketing management, 12th edn. Pearson Prentice-Hall, New Jersey

Lacey R (2015) Relationship marketing tools: understanding the value of loyalty programs. In: Parish JT, Deitz G, Morgan RM (eds) Handbook on research in relationship marketing. Edward Elgar Publishing, Cheltenham, pp 104-122 
Lacey R, Morgan RM (2008) Customer advocacy and the impact of b2b loyalty programs. J Bus Ind Mark 24(1):3-13

Lemon KN, Verhoef CV (2016) Understanding customer experience throughout the customer journey. J Market 80(6):69-96

Liu Y (2007) The long-term impact of loyalty programs on consumer purchase behavior and loyalty. J Market 71(4):19-35

Livingston JA (2005) How valuable is a good reputation? a sample selection model of internet auctions. Rev Econ Stat 87(3):453-465

Martín-Herrán G, McQuitty S, Sigué SP (2012) Offensive versus defensive marketing: what is the optimal spending allocation? Int J Res Mark 29(2):210-219

Nelson P (1974) Advertising as information. J Polit Econ 82(4):729-754

Nerlove M, Arrow J (1962) Optimal advertising policy under dynamic conditions. Economica 29:129-142

Noble SM, Esmark CL, Noble CH (2014) Accumulation versus instant loyalty programs: the influence of controlling policies on customers' commitments. J Bus Res 67(3):361-368

Nunes JC, Drèze X (2006) Your loyalty program is betraying you. Harvard Bus Rev 84(4):124-131

O’Brien L, Jones C (1995) Do rewards really create loyalty? Long Range Plann 28(4):130-130

Oliver RL (2014) Satisfaction: a behavioral perspective on the consumer. Routledge, Abingdon

O'Malley L (1998) Can loyalty schemes really build loyalty? Market Intel Plann 16(1):47-55

Reinartz W (2006) Understanding customer loyalty programs. In: Krafft M, Mantrala M (eds) Retailing in the 21st century. Springer, Berlin, pp 361-379

Roehm ML, Pullins EB, Roehm HA Jr (2002) Designing loyalty-building programs for packaged goods brands. J Market Res 39(2):202-213

Rust RT, Miu C (2006) What academic research tells us about service. Commun ACM 49(7):49-54

Schiesser W, Griffiths G (2009) A compendium of partial differential equation models: method of lines analysis with matlab. Cambridge University Press, New York

Sharp B, Sharp A (1997) Loyalty programs and their impact on repeat-purchase loyalty patterns. Int J Res Mark 14(5):473-486

Simon J, Arndt J (1980) The shape of the advertising response function. J Advert Res 20(4):11-28

Steinhoff L, Palmatier RW (2016) Understanding loyalty program effectiveness: managing target and bystander effects. J Acad Market Sci 44(1):88-107

Suh JC, Yi Y (2012) Do consumption goals matter? the effects of online loyalty programs in the satisfactionloyalty relation. Psychol Market 29(8):549-557

Yi Y, Jeon H (2003) Effects of loyalty programs on value perception, program loyalty, and brand loyalty. J Acad Market Sci 31(3):229-240 